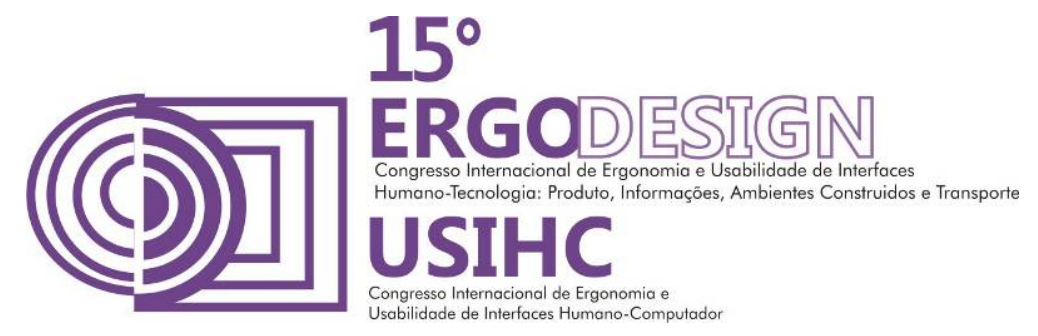

\title{
A QUALIDADE DA ACESSIBILIDADE ESPACIAL EM CONDOMÍNIOS RESIDENCIAIS MULTIFAMILIARES DE BAIXO CUSTO
}

\section{THE QUALITY OF SPATIAL ACCESSIBILITY IN MULTIFAMILY RESIDENTIAL CONDOMINIUMS OF LOW COST}

\author{
PRADO, Bruna de Brito (1); \\ LELIS, Viviane Frascareli (2); \\ AMARO, Eliane Katayama Pricoli (3); \\ MAGAGNIN, Renata Cardoso (4) \\ (1) Universidade Estadual Paulista, Mestranda \\ e-mail:bruna@faac.unesp.br \\ (2) Universidade Estadual Paulista, Mestranda \\ e-mail: viviane.lelis@uol.com.br \\ (3) Universidade Estadual Paulista, Arquiteta e Urbanista \\ e-mail: elianekatayama@gmail.com \\ (4) Universidade Estadual Paulista, Prof ${ }^{a}$.Dra \\ e-mail: magagnin@faac.unesp.br
}

\begin{abstract}
RESUMO
Atualmente, a qualidade das construções habitacionais vem sendo prejudicada, devido ao interesse no barateamento da construção; assim, questões como a acessibilidade espacial acabam sendo desconsideradas. Este artigo apresenta uma análise comparativa sobre o grau de satisfação dos usuários em relação à qualidade da acessibilidade espacial em dois condomínios residenciais multifamiliares de baixo custo localizados em Bauru, Estado de São Paulo. A metodologia envolveu levantamentos fotográficos, métricos, aplicação de questionário e do protocolo de acessibilidade. Os resultados demonstraram que os dois condomínios têm problemas graves de acessibilidade, sendo necessária uma adequação espacial para melhorar a qualidade e a segurança nos deslocamentos.
\end{abstract}

Palavras-chave: acessibilidade espacial, condomínios residenciais multifamiliares de baixo custo, avaliação pós-ocupação

\section{ABSTRACT}

Currently, the quality of the housing constructions has been impaired due to the interest in the price 


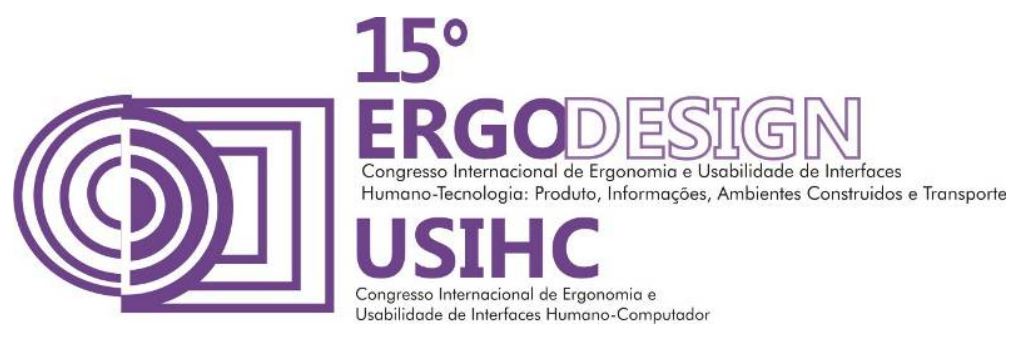

reduction of construction; so, the issues such as spatial accessibility are eventually disregarded. This paper presents a comparative analysis of the degree of user satisfaction regarding the quality of spatial accessibility in two multifamily residential low cost condominiums, located in Bauru, São Paulo State. The methodology involved photographic and metric surveys, questionnaire and accessibility protocol. The results showed that the two condominiums have serious accessibility problems, requiring a spatial adequacy to improve the quality and safety during the displacements.

Keywords: spatial accessibility, low cost housing, post-occupancy evaluation (POE)

\section{INTRODUÇÃO}

Atualmente, a questão habitacional é um dos graves problemas que estão em destaque no cenário nacional. Além do déficit habitacional, outros fatores têm contribuído para agravar o problema habitacional no país. Dentre eles destacamos: redução dos ambientes (das dimensões físicas), diminuição da qualidade do material empregado na sua construção, além da padronização das unidades (PEREIRA, 2007).

A Constituição Federal de 1988 declara que a moradia deve garantir as necessidades mínimas a uma família para que essa tenha condições mínimas de habitabilidade, usabilidade, conforto, segurança, bem-estar, integridade física, entre outros, na tentativa de garantir melhores condições de vida (BRASIL, 1988). A Norma Técnica Brasileira NBR 15575-1 acrescenta a essas condições os itens de conforto ambiental e a acessibilidade (ABNT, 2010).

Programas de baixo custo para construção de moradias surgiram no Brasil na década de 60 para a redução do déficit habitacional. Segundo Bonduki (2011) quando a arquitetura moderna se envolveu com a habitação social houve uma preocupação com o barateamento da construção, com a racionalização, industrialização e consequentemente novas tipologias com redução de custos e dimensões mínimas. Dessa forma, aspectos como a acessibilidade são deixados em segundo plano para enfatizar apenas uma construção de baixo custo o que não necessariamente deveria ser vinculada à baixa qualidade habitacional.

Dischinger, Bins Ely e Piardi (2012) definem acessibilidade espacial como algo além da locomoção até um lugar desejado, esse local deve permitir que o usuário compreenda sua função, organização e relações espaciais, assim como participar das atividades desenvolvidas ali, tudo isso com segurança, conforto e independência. A análise da acessibilidade nas áreas comuns de condomínios habitacionais é verificada por meio de fatores como adequação de escadas, rampas, estacionamentos, acessos da rua ao condomínio residencial, às unidades habitacionais, às áreas de convivência, sanitários, etc.

Carli (2010) conclui que um dos grandes desafios do ambiente doméstico é compensar as limitações e promover a independência no uso, enfatiza, ainda, que um bom projeto habitacional prevê a diversidade das pessoas que irão utilizá-lo e só pode ser considerado de qualidade quando suportar as pessoas e suas necessidades, considerando as limitações decorrentes do envelhecimento, por alguma deficiência ou algo temporário, fatores comuns ao longo da vida das pessoas.

Diante desta realidade, este artigo tem como objetivo apresentar uma análise comparativa sobre o grau de satisfação dos usuários em relação à acessibilidade em dois condomínios 


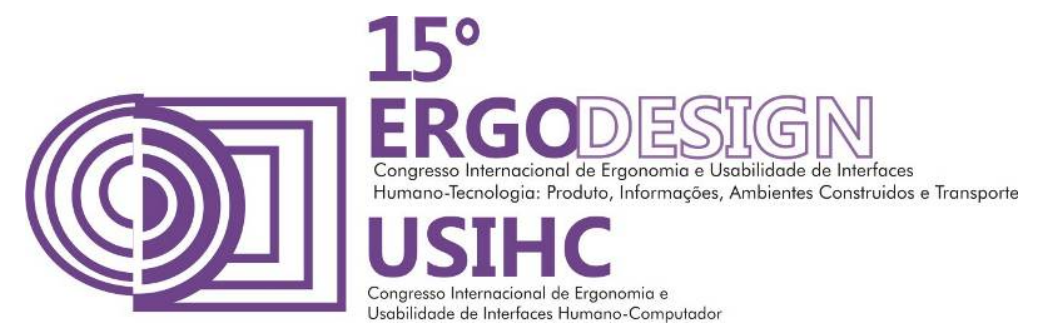

residenciais multifamiliares de baixo custo implantados na cidade de Bauru, Estado de São Paulo.

\section{2. ÁREA DE ESTUDO}

Para a análise da qualidade espacial de edifícios residenciais de baixo custo foram utilizados como estudo de caso dois edifícios residenciais construídos no município de Bauru (localizado na região centro oeste do Estado de São Paulo - Figura 1a).

Os dois condomínios foram projetados e implantados pela mesma construtora, sendo que o Condomínio 1 começou a ser utilizado no ano de 2010 e o Condomínio 2 no ano de 2013. O primeiro conjunto foi implantado em uma quadra localizada em um bairro residencial da zona oeste da cidade, e o segundo em uma área de vazio urbano, na região sul da cidade, próximo a uma importante rodovia que dá acesso ao município de Bauru (Figura 1b e 1c).
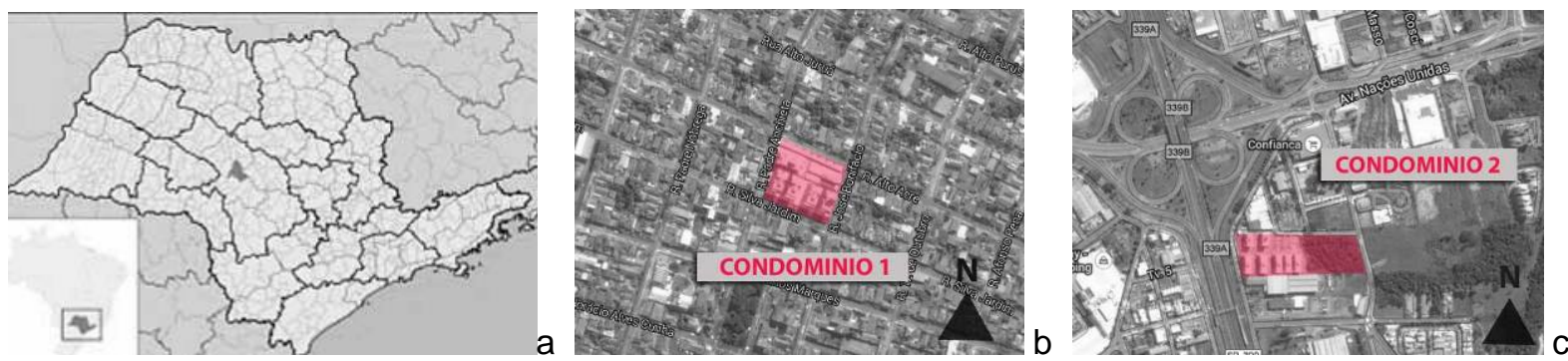

Figura 1 a, b, c - Localização de Bauru no Estado de São Paulo (a); Localização do Condomínio 1 (b); Localização do Condomínio 2 (c)

Fonte: Adaptado do Google Maps, 2015

O Condomínio 1 tem 120 apartamentos distribuídos em 5 edifícios de 5 pavimentos com apartamentos de 2 e 3 dormitórios, cada bloco tem 6 apartamentos por pavimento, sendo que os dois últimos pavimentos são caracterizados por apartamentos do tipo duplex. As áreas comuns são: estacionamento, portaria, playground, salão de festas e corredores externos aos blocos. O Condomínio 2 possui 260 apartamentos de 1, 2 e 3 dormitórios e não há a tipologia duplex. Os apartamentos são dispostos em 7 blocos de 5 pavimentos, os blocos de 1 a 5 tem 8 apartamentos por pavimento e os blocos 6 e 7,6 apartamentos por pavimento. As áreas comuns compreendem: estacionamento, portaria, playground, corredores externos aos blocos, quadra poliesportiva, espaço gourmet e espaço fitness (ver Figura 2a e 2b). 

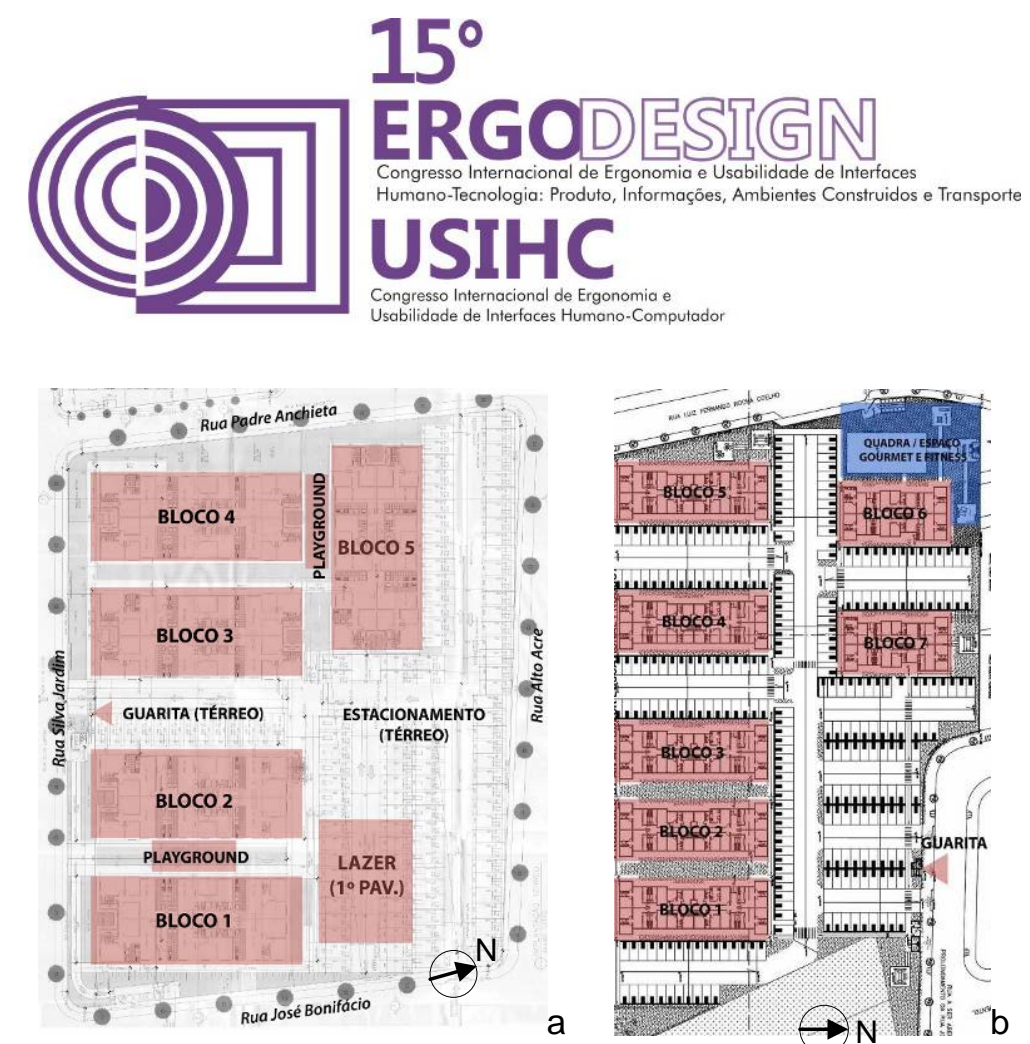

Figura 2 a, b - Implantação do Condomínio 1 (a) e Implantação Condomínio 2 (b) Fonte: adaptado do projeto original

Os dois condomínios residenciais foram escolhidos por apresentar características semelhantes, tais como: edificações de mais de um pavimento, sem elevador, tipologias construtivas semelhantes e por serem projetados e executados pela mesma construtora.

\section{METODOLOGIA}

Os instrumentos de pesquisa utilizados neste estudo de caso foram: revisão bibliográfica; legislação e normas técnicas sobre o assunto estudado; levantamento fotográfico; métrico; técnicas de Avaliação Pós-Ocupação que permitiu avaliar o comportamento, e o grau de satisfação dos usuários em relação à acessibilidade através da utilização de questionário e aplicação de um protocolo de acessibilidade.

O grau de satisfação dos usuários foi analisado através da utilização de questionários. Para a definição do universo de análise utilizou-se como referência os estudos de Ornstein e Romero (2003). Foi adotada uma margem de erro de 10\% e um nível de confiança de 95,5\%, o que resultou numa amostra mínima final de 80 unidades. A aplicação dos questionários foi realizada entre os meses de junho e julho de 2014. No Condomínio 1 foram aplicados 41 questionários $(29,29 \%$ da população) e no Condomínio 2 foram aplicados 61 questionários $(23,46 \%$ da população), sendo que 37 deles foram respondidos por formulários on-line.

As questões eram compostas de respostas abertas e fechadas (múltipla escolha) que permitiram identificar através de parâmetros quantitativos e qualitativos, o perfil dos usuários e avaliar a acessibilidade nos dois condomínios. Para avaliar o grau de acessibilidade sob o ponto de vista dos usuários foi utilizado o Método de Análise Multicritério; em particular, 0 Método da Escala de cinco pontos (ótimo a péssimo); onde o valor 1 (péssimo), 2 (ruim), 3 (regular), 4 (bom), e 5 (ótimo). A análise foi realizada utilizando o ranking dos indicadores de nível de importância. Inicialmente, foi calculado o peso médio de cada critério pelo avaliador. Posteriormente, foram realizados os cálculos dos valores médios dos pesos encontrados pelos indicadores avaliados e definidos os seus rankings. A última parte do questionário permitiu que 


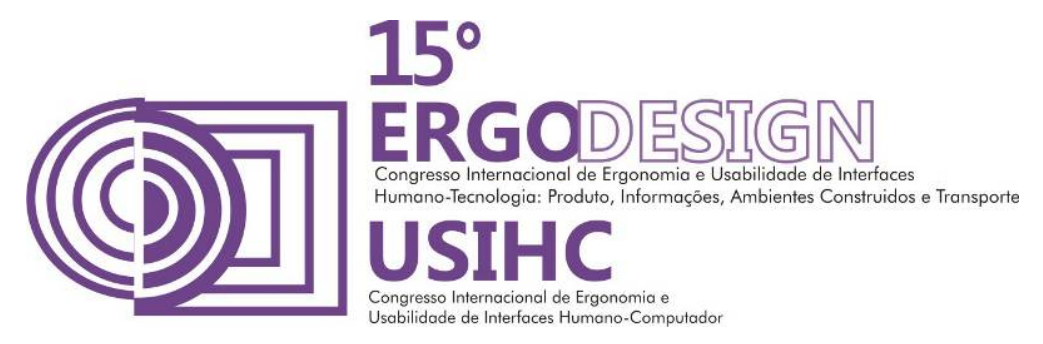

o usuário relatasse se já teria sofrido algum acidente relacionado à acessibilidade espacial.

O protocolo de acessibilidade utilizado foi desenvolvido por Dischinger, Bins Ely e Piardi (2012) e Pereira (2007). Nele são consideradas as seguintes questões para avaliação: acessos, circulações horizontais e verticais, circulações internas, qualidade dos pisos, sanitários para pessoas com deficiência, equipamentos de controle de acesso, controle de portas e janelas, área de aproximação e de manobras para cadeirantes, altura de instalações sanitárias, entre outros.

\section{ANÁLISE DOS DADOS}

Neste artigo, a avaliação dos dois condomínios foi realizada tendo como referência apenas as áreas de uso comum, ou seja, foram analisados os seguintes ambientes: entrada do condomínio, acesso do estacionamento ao bloco de habitação, rampas de acesso, escadas, circulação interna nos blocos, estacionamento para pessoa com deficiência e sanitários acessíveis de uso comum.

\subsection{Análise dos questionários}

A maioria dos moradores entrevistados no Condomínio 1 é de mulheres (78\%) enquanto que os homens representaram $22 \%$ dos inquiridos; no Condomínio 2 o resultado foi de $53 \%$ de homens e $47 \%$ de mulheres. Com relação à faixa etária, fator este que pode comprometer a acessibilidade espacial nestas edificações, foram encontrados os seguintes resultados: nos dois condomínios 10\% dos entrevistados eram compostos por jovens entre 16 a 25 anos; na faixa etária entre 26 e 40 anos foram 32\% no Condomínio 1 e 77\% no Condomínio 2, o que demonstra um perfil de morador mais jovem e adulto nesse condomínio; com relação as pessoas entre 41 e 64 anos, os dados mostraram que 36\% residem no Condomínio 1 e $10 \%$ no Condomínio 2; e aqueles com 65 anos ou mais representaram 22\% dos entrevistados no Condomínio 1 e 3\% no Condomínio 2, demonstrando que a população do Condomínio 1 é composta prioritariamente por adultos e idosos.

\subsubsection{Análise dos moradores em relação à acessibilidade}

A segunda etapa consistiu na análise da acessibilidade sob a ótica dos moradores. Para esta análise utilizou-se como referência técnicas de avaliação multicritério, nas quais as avaliações dos moradores de cada condomínio foram ordenadas em função dos itens mais problemáticos ou de urgente resolução para aqueles que não apresentam problemas (ver Tabela 1).

Tabela 1 - Ranking de acessibilidade

\begin{tabular}{lcccc}
\hline \multirow{2}{*}{ Indicadores } & \multicolumn{2}{c}{ Média } & \multicolumn{2}{c}{ Ranking / Ordem } \\
\cline { 2 - 5 } & Condomínio 1 Condomínio 2 & Condomínio 1 Condomínio 2 \\
\hline $\begin{array}{l}\text { acesso dos pedestres da guarita até as } \\
\text { habitações }\end{array}$ & 0,126 & 0,113 & $\mathbf{1 1}$ & $\mathbf{9}$ \\
\hline $\begin{array}{l}\text { acesso da sua vaga de garagem até sua } \\
\text { habitação }\end{array}$ & 0,109 & 0,120 & $\mathbf{7}$ & $\mathbf{1 1}$ \\
\hline
\end{tabular}




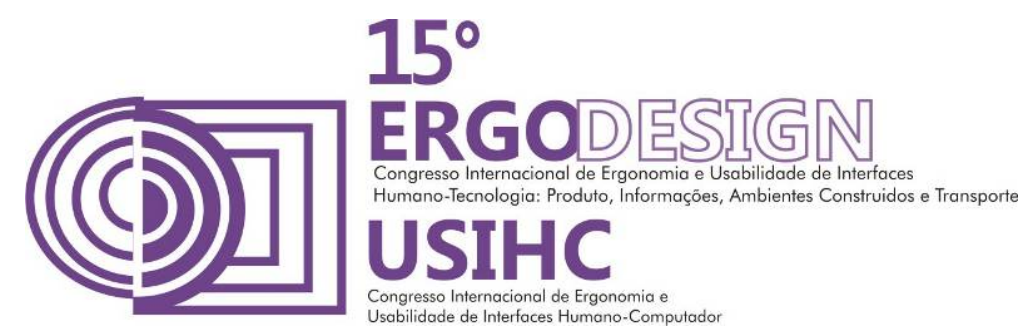

\begin{tabular}{|c|c|c|c|c|}
\hline \multirow{2}{*}{ Indicadores } & \multicolumn{2}{|c|}{ Média } & \multicolumn{2}{|c|}{ Ranking / Ordem } \\
\hline & Condomín & domínio 2 & Condom & omínio 2 \\
\hline $\begin{array}{l}\text { manutenção do piso das áreas comuns, } \\
\text { incluindo caminho de pedestres entre os } \\
\text { blocos }\end{array}$ & 0,107 & 0,109 & 6 & 7 \\
\hline $\begin{array}{l}\text { largura dos caminhos de pedestres nas } \\
\text { áreas comuns }\end{array}$ & 0,122 & 0,115 & 10 & 10 \\
\hline $\begin{array}{l}\text { sanitários para deficientes físicos nas } \\
\text { áreas comuns }\end{array}$ & 0,086 & 0,096 & 3 & 4 \\
\hline $\begin{array}{l}\text { segurança das escadas de acesso aos } \\
\text { apartamentos (risco de acidentes) }\end{array}$ & 0,090 & 0,094 & 4 & 3 \\
\hline $\begin{array}{l}\text { segurança das rampas de acesso das } \\
\text { áreas comuns (risco de acidentes) }\end{array}$ & 0,105 & 0,097 & 5 & 5 \\
\hline $\begin{array}{l}\text { segurança do bloco de habitação (risco } \\
\text { de acidentes) }\end{array}$ & 0,115 & 0,108 & 9 & 6 \\
\hline $\begin{array}{l}\text { segurança das áreas comuns quanto ao } \\
\text { risco de acidentes }\end{array}$ & 0,113 & 0,109 & 8 & 8 \\
\hline $\begin{array}{l}\text { adaptação do condomínio ao uso por } \\
\text { deficientes físico e visual }\end{array}$ & 0,067 & 0,067 & 1 & 1 \\
\hline $\begin{array}{l}\text { adaptação do condomínio para pessoas } \\
\text { com mobilidade reduzida (idosos, } \\
\text { gestantes, crianças, alguém carregando } \\
\text { coisas pesadas ou empurrando } \\
\text { carrinhos) }\end{array}$ & 0,075 & 0,071 & 2 & 2 \\
\hline
\end{tabular}

Analisando os dados apresentados na Tabela 1 pode-se constar que os itens que obtiveram as cinco primeiras posições no ranking foram: adaptação do condomínio ao uso por deficientes físico e visual, adaptação do condomínio para pessoas com mobilidade reduzida, sanitários para deficientes físicos nas áreas comuns, segurança das escadas de acesso aos apartamentos quanto ao risco de acidentes, e segurança das rampas de acesso das áreas comuns quanto ao risco de acidentes. Observou-se também que a maioria deles obteve a mesma avaliação (ranking) nos dois condomínios (posição 1, 2 e 5).

Com relação à adaptação do condomínio ao uso por deficientes físicos, visuais e com mobilidade reduzida identificou-se a ausência de elevador, que impossibilita o acesso a todos os pavimentos, a falta de sinalização tátil nas áreas comuns, grande inclinação de rampas, falta de área de manobras suficiente nos sanitários. Os sanitários apresentam problemas de dimensões e alturas de instalação de acessórios e barras de apoio, quando há. A escada tem os degraus com espelhos de tamanhos variáveis e vazados, o que causa insegurança, assim como a ausência de iluminação que é ativada somente por sensor de presença. As rampas apresentam ausência de corrimão, superfície irregular e, em sua maioria, inclinação elevada.

Com relação ao item do questionário que permitia ao entrevistado indicar os elementos associados à acessibilidade espacial que deveriam ser melhorados ou mudados nos dois condomínios, a resposta mais citada foi "criar um caminho apenas para pedestres no estacionamento" em ambos, seguido por "colocar corrimãos em rampas e escadas" e "barreiras físicas nas áreas comuns" no Condomínio 1 e no Condomínio 2, em segundo lugar ficou a 


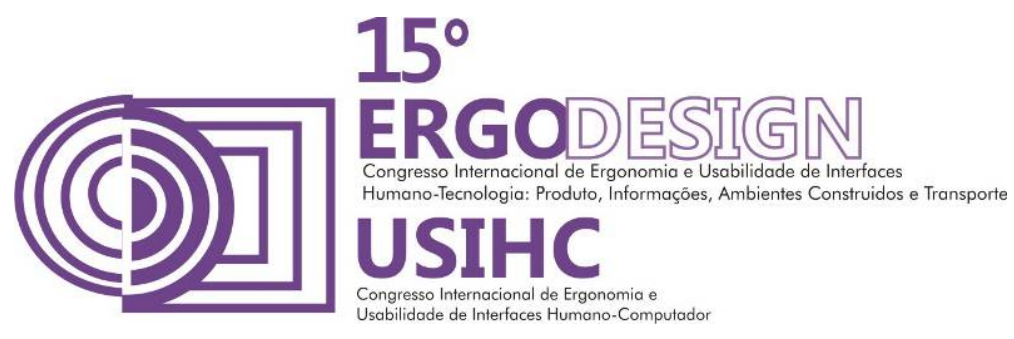

"conservação do piso da área comum" e em terceiro "diminuir a inclinação de rampas".

\subsection{Análise da acessibilidade realizada pelos especialistas}

A segunda etapa consistiu da análise da acessibilidade nas áreas comuns utilizando como referência os protocolos de acessibilidade desenvolvidos por Dischinger, Bins Ely e Piardi (2012). Nesta pesquisa foram utilizados apenas os tópicos que se adequavam aos edifícios habitacionais; sendo considerados também os itens relativos à norma técnica de acessibilidade NBR 9050 e o Decreto Federal 5.296/2004. Esta análise foi dividida em 5 temáticas: acessos, circulação interna, rampas, estacionamento para deficientes físicos e sanitários acessíveis.

Os acessos foram compreendidos pelos seguintes elementos: calçadas do entorno do condomínio, acesso da calçada à guarita, equipamentos para entrada no edifício, circulação nos pátios e caminhos de pedestre dentro do condomínio. Avaliando o item acessos, no que se refere às calçadas do entorno do condomínio, pode-se perceber que há interferências na faixa livre de circulação, sendo que no Condomínio 1, apesar de a faixa livre de circulação ter largura de $1,20 \mathrm{~m}$, a sensação é de se ter um espaço menor, devido à altura e largura da vegetação existente, que impossibilitam a passagem de duas pessoas ao mesmo tempo na calçada (Figura 3a). No Condomínio 2 a calçada tem 1,50m de largura total, entretanto a faixa de mobiliário ocupa 0,50m, deixando apenas 1,00m de faixa livre de circulação (Figura 3b), o lixo do condomínio prejudica a circulação na calçada, a síndica relatou que muitas vezes o lixeiro não passa, pois reclama que a porta de acesso ao compartimento de lixo do condomínio foi mal dimensionada por ser muito estreita.

Com relação ao acesso da calçada à guarita, no Condomínio 1 existe uma rampa com inclinação inadequada que dificulta o acesso a todos os moradores, Figura 7a. No Condomínio 2 esse acesso é adequado.

Sobre os equipamentos para entrada no edifício, os interfones dos condomínios são instalados com altura inadequada para pessoas com deficiência física (cadeirante) ou de baixa estatura. No Condomínio 1 a altura é de 1,40m; enquanto no Condomínio 2 é de 1,62m. Tomando-se como parâmetro a altura de maçanetas de portas de $1,10 \mathrm{~m}$ no máximo, entende-se que o usuário com deficiência não consegue acessar o interfone dos condomínios, conforme Figura $4 a$ e $4 b$. Os pisos dos pátios estão de acordo com o protocolo, pois nos dois condomínios foi perguntado ao síndico/zelador sobre a questão do piso em dias de chuva e ambos relataram não serem escorregadios.

Em relação à circulação nos pátios e caminhos de pedestres, os dois condomínios não possuem pisos táteis direcionais de alerta (ver Figuras 5 a e 5b), o que dificulta a locomoção de um deficiente visual, seja ele morador ou visitante, nas áreas comuns do condomínio. A circulação nos pátios e nos caminhos de pedestres é realizada em meio aos carros estacionando ou saindo das garagens, não há um caminho separado para os pedestres nos dois condomínios. 

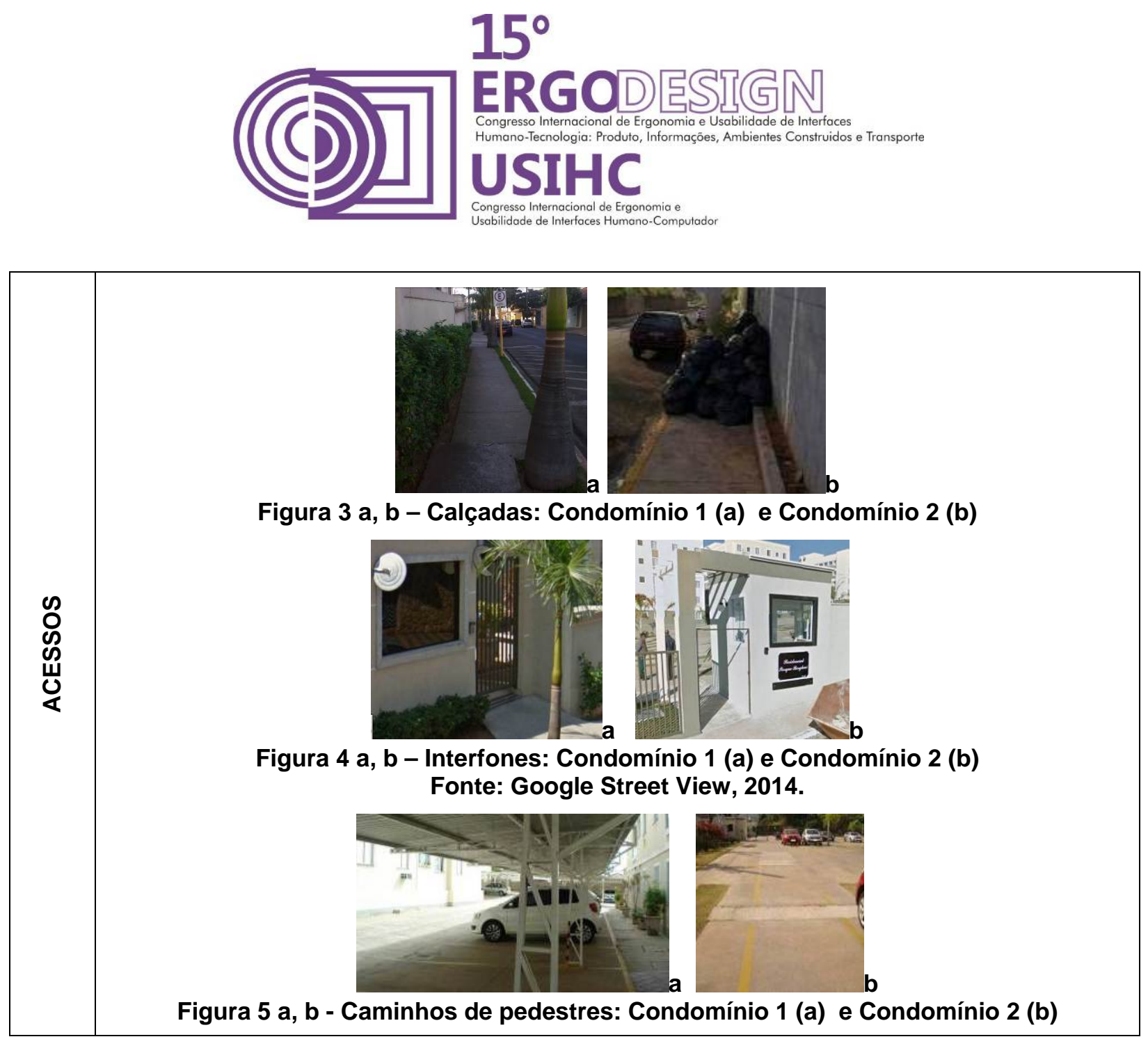

De forma geral, o Condomínio 1 apresentou 7 itens (ou seja, 50\% do total) do protocolo de acessos, enquanto no Condomínio 2 foram apenas 4 itens, que correspondeu a apenas 28,57\% dos itens avaliados.

O tema circulação interna foi compreendido por: características das portas de acesso aos apartamentos, dos corredores de circulação internos aos blocos e das escadas. Em relação às portas de acesso aos apartamentos os itens foram praticamente todos atendidos, exceto em dois quesitos, o tipo de maçaneta que como padrão é de alavanca, mas no Condomínio 1 alguns moradores trocaram a maçaneta para o tipo redondo e os capachos, que na maioria dos apartamentos dos dois condomínios são soltos, o que torna a entrada escorregadia e perigosa, o ideal seria se houvesse um desnível no piso onde o capacho pudesse ser encaixado.

Sobre os corredores de circulação internos aos blocos nos dois condomínios o conjunto de aparatos para casos de incêndio estão pendurados abaixo de 2,10m e tornam-se obstáculos nos corredores de circulação internos aos blocos (ver Figura 6a e 6b). A sinalização de saída de emergência existe nos blocos do Condomínio 2, mas não há sonoro, apenas visual, enquanto que no Condomínio 1 não há ao menos sinalização visual.

As escadas da circulação interna dos blocos têm o formato parecido nos dois condomínios, porém são construídas de material diferente. No Condomínio 1 ela é de concreto e no Condomínio 2 de ardósia (Figuras 6c e 6d), com degraus, cujos espelhos são abertos; e, 


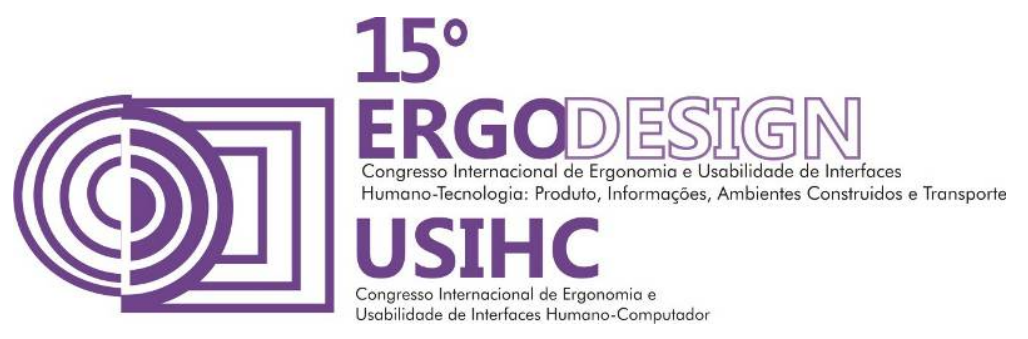

portanto, não estão de acordo com a NBR 9050, pois não são seguras para os moradores. Outro problema refere-se ao tamanho dos espelhos e pisos que são de altura variável, o que torna a escada insegura apesar de haver corrimãos dos dois lados. Além das escadas internas ao bloco, no Condomínio 1 também foi analisada a escada de acesso ao compartimento de lixo (Figura 6e), que não existia no projeto original e que foi construída pelo atual zelador. Ela também apresentou variações na altura do espelho e do piso. Identificou-se ausência de piso tátil antes do início das escadas, o que torna os locais inseguros para deficientes visuais.

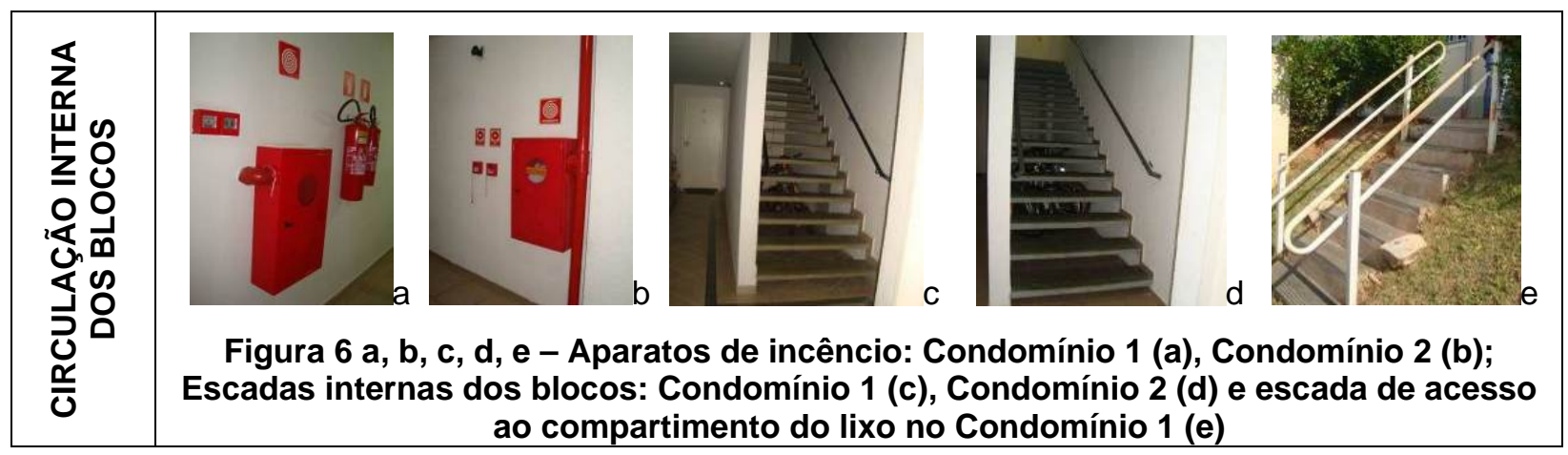

Sintetizando esse tópico de circulação interna, o Condomínio 1 apresentou 15 requisitos $(55,55 \%)$ e o Condomínio 2, 19 requisitos (70,37\%), sendo que os itens que não tinham elementos para análise foram desconsiderados dessa contagem.

As questões de acessibilidade relativas às características das rampas de acesso das áreas comuns foi analisada em 6 rampas no Condomínio 1 e 11 rampas no Condomínio 2. Entre os itens de maior relevância estão: a largura das rampas, o piso, a instalação de corrimão dos dois lados, a inclinação e a sinalização tátil no início e término das rampas. No item supracitado acesso do pedestre à guarita, da temática de acessos, este elemento foi analisado nos dois objetos de estudo, sendo a inclinação da rampa de acesso do Condomínio 2 de 9,33\% e do Condomínio 1 de 25\%, (ver Figura 7a). Na parte de dentro do portão há também uma rampa com inclinação de 10\%. De acordo com a NBR 9050 a inclinação ideal é de 8,33\%, no caso de reformas, aceitável de $12 \%$, o que revela que a rampa de entrada do Condomínio 1 é um dos principais pontos críticos de acessibilidade.

No Condomínio 1, das 6 rampas analisadas, uma é de acesso ao salão de festas e as outras estão localizadas nas áreas de circulação de pedestres. A primeira é estreita por ter apenas $1,00 \mathrm{~m}$ de largura e pela presença de um guarda corpo alto, de alvenaria (Figura 7b e 7c). 0 piso tem características onduladas e o que demonstra ser inseguro. Há corrimãos em apenas um lado da rampa, sendo que este não possui continuidade, pois no primeiro trecho está do lado direito e no segundo do lado esquerdo, conforme demonstra a Figura 7d. Também não há sinalização tátil no início nem no término da rampa e sua inclinação é variável, o que não é adequado, mas apresenta inclinação nos quatro trechos, entre 5,66\% e 10\%, portanto esta de acordo com a norma técnica de acessibilidade. No entanto, o ideal seria que mantivesse a mesma inclinação do início ao fim. As outras rampas analisadas apresentaram inclinação adequada com exceção da vaga de estacionamento rápido que é utilizada como acesso ao bloco 5 que tem 13,33\% de inclinação e a rampa da calçada de acesso em frente à guarita, citada anteriormente. 


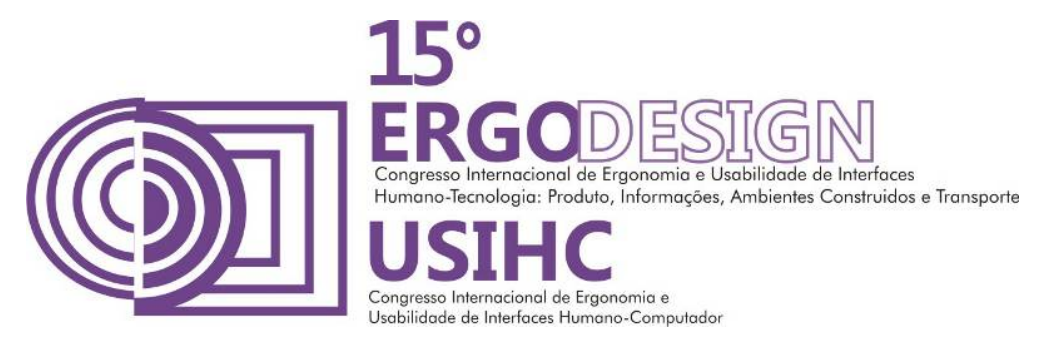

No Condomínio 2 a maioria das rampas serve de acesso aos blocos e 3 estão próximas ao espaço gourmet. Apenas duas rampas apresentam corrimão dos dois lados, enquanto algumas tem apenas de um lado e outras não tem em nenhum dos lados (Figura $8 \mathrm{c}$ e $8 d$ ). O piso é de concreto estampado com superfície irregular, o que dificulta a utilização por pessoas com deficiência ou mobilidade reduzida, também não há nenhuma sinalização tátil e a inclinação só é encontrada abaixo do nível estipulado pela NBR 9050 de 8,33\%, em 4 rampas, sendo que a mais perigosa tem $28,33 \%$ que é rampa de acesso ao espaço fitness (Figura 8 a) e 23,33\% na rampa de acesso do bloco 5 ao bloco 4 (Figura 8b).

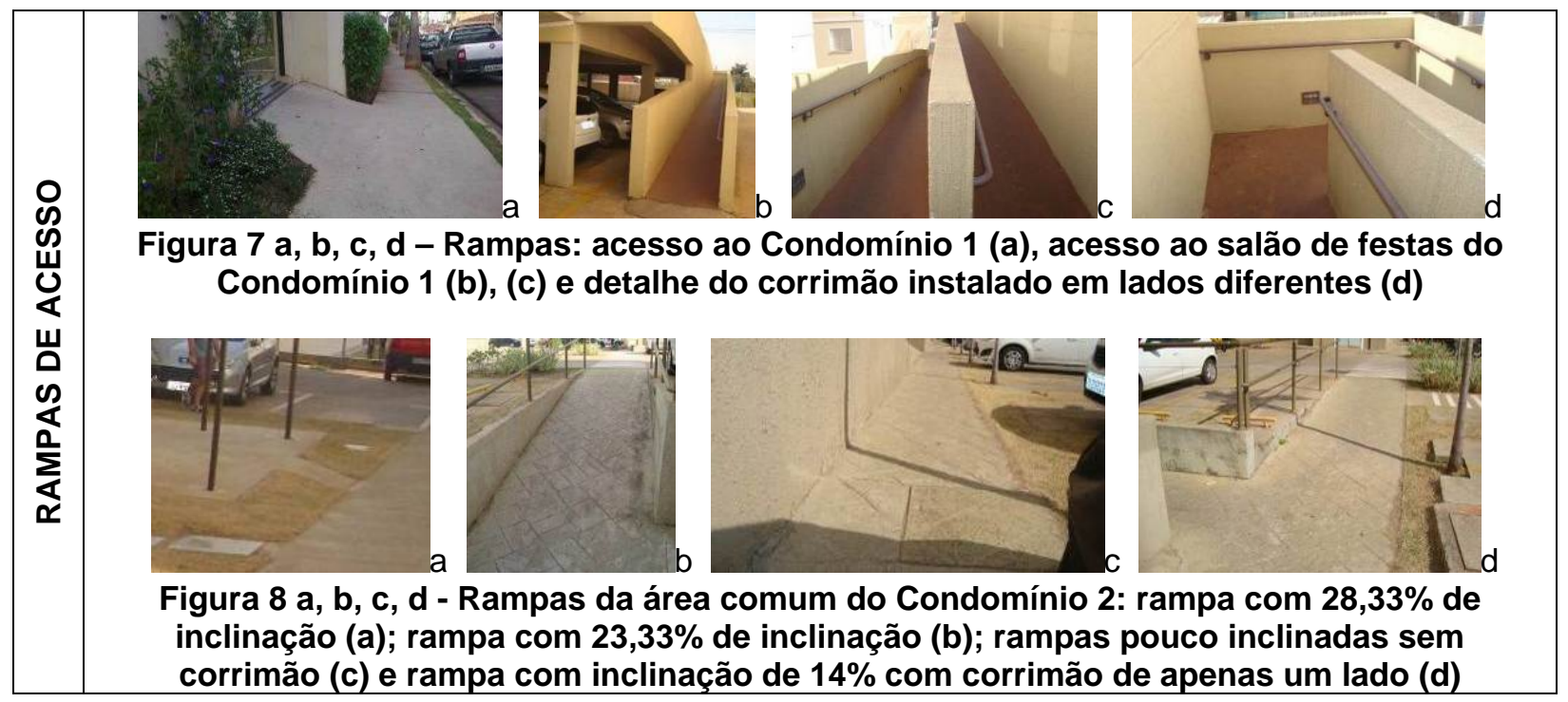

Do total de rampas analisadas, no Condomínio 1, 33,33\% estão fora do padrão de inclinação estipulado pela normativa e no Condomínio 2,63,64\% das rampas. O Condomínio 1 atendeu a 5 requisitos $(33,33 \%)$ do protocolo de rampas, enquanto o Condomínio 2 atendeu a 3 itens (25\%).

$\mathrm{Na}$ sequência foram analisados os elementos relacionados aos estacionamentos para deficientes físicos; fizeram parte desta análise os seguintes itens: existência de vagas externas no logradouro de localização do condomínio e internas ao condomínio, existência de sinalização das vagas, quantidade de vagas e existência de faixa de circulação.

Não há vagas externas no logradouro de localização do Condomínio 1, nem mesmo internas. No Condomínio 2 existe mais de 1\% de vagas destinadas a cadeirantes na parte interna, mas não há vagas para portadores de mobilidade reduzida como idosos. As vagas existentes são vinculadas a determinados apartamentos (localizados no andar térreo, 1 em cada edifício) que foram projetados para pessoas com deficiência física ou mobilidade reduzida.

Sobre a sinalização das vagas do Condomínio 2, não há sinalização vertical e há sinalização horizontal, entretanto, o símbolo internacional, em algumas vagas é marcado apenas pelo quadrado azul sem a representação gráfica do cadeirante e, suas dimensões, não estão de acordo com a NBR 9050 (ver Figura 9a, 9b e 9c). A faixa de circulação está presente em todos os estacionamentos delimitados para pessoas com deficiência física nesse condomínio. 

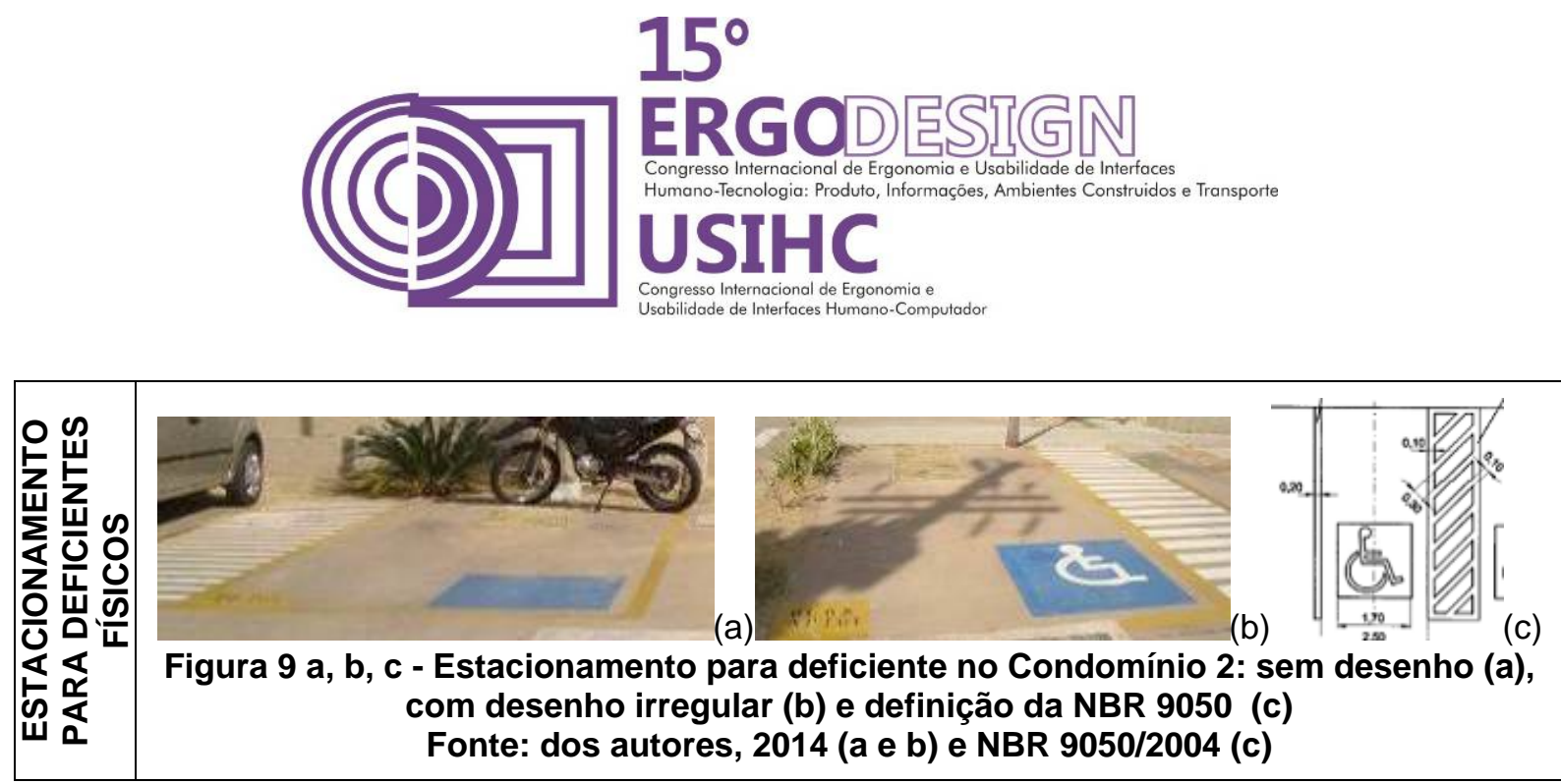

No protocolo, o item estacionamento, do Condomínio 2 atendeu a 6 requisitos (75\%) do elenco total deste protocolo. No Condomínio 1 não foram encontradas vagas destinadas às pessoas com deficiências.

O último elemento avaliado referiu-se a existência de sanitários acessíveis nas áreas comuns. Nesta avaliação foram verificados os seguintes itens: áreas de manobra; área de transferência; presença e alturas de instalação das barras de apoio; tipologia de lavatório; as alturas dos acessórios; tipologia de piso antiderrapante, regular e estável e; tipologia de torneiras.

No Condomínio 1 foram encontrados sanitários de uso comum apenas no salão de festas e no Condomínio 2 no espaço gourmet. A área da manobra no interior dos sanitários para usuários de cadeira de rodas nos dois condomínios não são suficientes para o giro de $360^{\circ}(1,50 \mathrm{~m} x$ 1,20m - NBR 9050). No Condomínio 1 o espaço encontrado foi de 1,20m x 1,10m e no Condomínio 2 de 1,50m x 1,10m. Também não foi encontrada área de transferência da cadeira de rodas para o vaso sanitário adequada; a norma técnica estabelece uma área de $0,80 \mathrm{~m} x$ 1,20m; no entanto, no Condomínio 1 a largura encontrada foi de $0,40 \mathrm{~m} \times 1,40 \mathrm{~m}$ e no Condomínio 2 de $0,75 \mathrm{~m} \times 1,20 \mathrm{~m}$.

No sanitário do Condomínio 1 não há barras de apoio e no Condomínio 2 apesar de ter a instalação não obedece a NBR 9050 (ABNT, 2004) em relação às alturas e distâncias. A barra da parede dos fundos foi instalada distando $8 \mathrm{~cm}$ da caixa acoplada do vaso sanitário, quando 0 mínimo é de $15 \mathrm{~cm}$, a barra de apoio lateral foi instalada inclinada sendo a altura menor de $0,61 \mathrm{~m}$ e a maior de $0,84 \mathrm{~m}$, diferente do que estabelece a norma técnica: altura para os dois lados de 0,75m (ver Figura 10a e 10b).

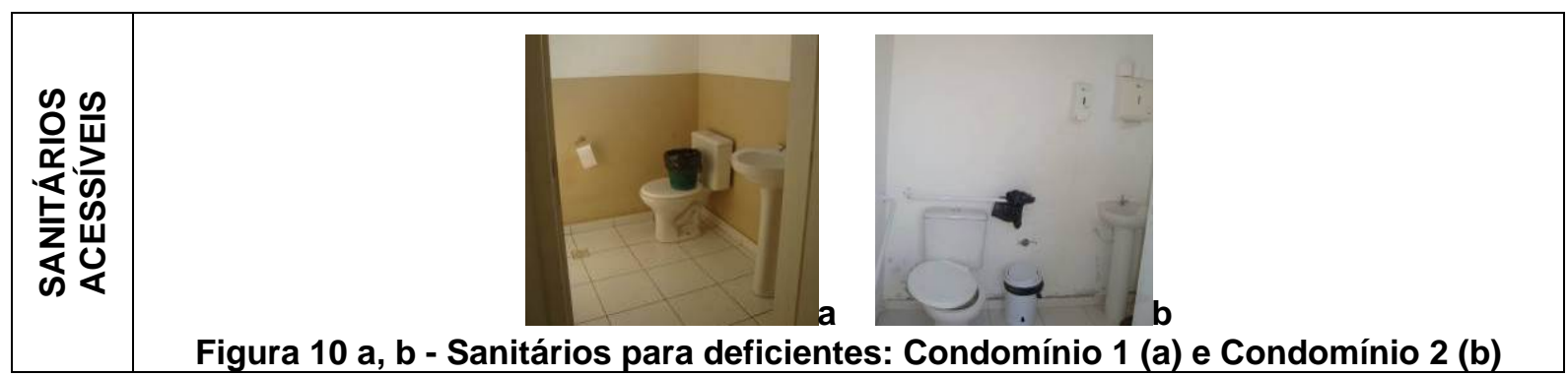

Nos dois condomínios o lavatório é do tipo "coluna", o certo seria instalar um lavatório sem coluna para permitir maior área de aproximação do cadeirante. Sobre os acessórios no Condomínio 1 não há nenhum instalado, nem papeleira, tampouco saboneteira e no 


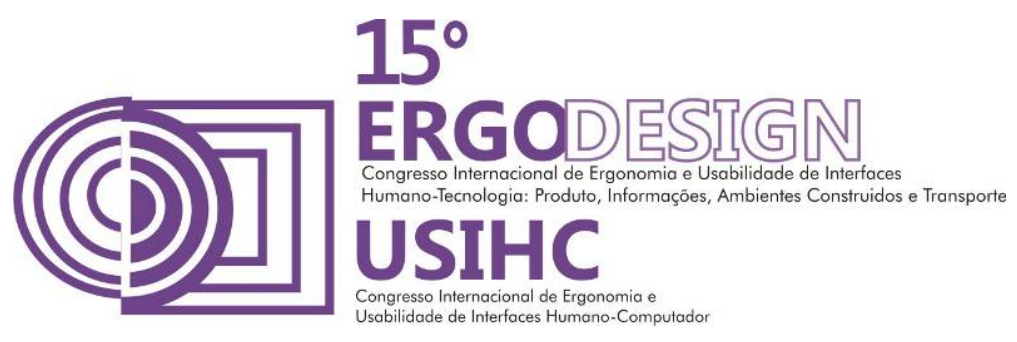

Condomínio 2 estão todos instados a uma altura superior do que 1,20m, máximo estipulado na NBR 9050. Os pisos dos sanitários dos dois condomínios são lisos e as torneiras são de girar manuais, quando o ideal seria de alavanca com sensor eletrônico. Sintetizando, o Condomínio 1 atendeu a 11 itens (ou 50\%) do protocolo sobre a acessibilidade nos sanitários e 0 Condomínio 2 atendeu a 16 itens (ou 61,54\%).

$\mathrm{Na}$ avaliação do ranking os moradores demonstraram ter consciência de que os condomínios não estão adequados para pessoas com deficiência ou mobilidade reduzida, sendo esses dois os aspectos que ficaram no topo do ranking. Apesar de no ranking o item de avaliação dos caminhos de pedestres ter sido bem avaliado, ficou entre os 3 melhores, nas observações feitas pelos moradores durante a aplicação dos questionários havia preocupação com a segurança, falta de cobertura e falta de delimitação dos caminhos de pedestres dentro do estacionamento e das áreas comuns dos condomínios. Como comprovação tem-se o resultado da questão de possíveis melhorias/mudanças que poderiam ser feitas nos condomínios, na qual a criação de caminhos exclusivos para pedestres foi o primeiro item mais votado nos dois condomínios.

$\mathrm{Na}$ aplicação do protocolo de acessibilidade o Condomínio 2 apresentou melhor desempenho na questão de acessibilidade do que o Condomínio 1, a diferença entre os dois foi de 10 itens. Ainda foi possível aferir que enquanto o Condomínio 1 tem atende mais requisitos nas temáticas de acessos e rampas de acesso, o Condomínio 2 apresenta maior desempenho nas temáticas de circulação interna dos blocos, estacionamento e sanitários acessíveis. Cabe ressaltar que o Condomínio 2 é mais novo e talvez por esse motivo tenha tido maior rigor no atendimento às normativas e legislações referentes à acessibilidade.

A ausência de elevador nos condomínios impede a acessibilidade total a todos os andares por moradores e visitantes das habitações com ou sem mobilidade reduzida ou deficiência, salienta-se que carregar compras do supermercado é uma mobilidade reduzida temporária e todos os moradores passam por essa situação rotineiramente. A comparação entre o projeto e a execução dos dois condomínios ressaltou a questão de adaptações do projeto no canteiro de obras, principalmente questões de desníveis: rampas que desaparecem ou degraus que se tornam rampas muito íngremes; essas alterações prejudicam a qualidade da acessibilidade. Assim, a qualidade da acessibilidade só pode ser garantida quando incorporada logo no início do projeto arquitetônico e verificada sua execução na obra.

\section{CONSIDERAÇÕES FINAIS}

A partir desta pesquisa pode-se identificar e conhecer os principais problemas que estão associados ao barateamento das construções habitacionais no Brasil. Além de problemas construtivos e diminuição dos ambientes a questão da acessibilidade é outro fator que se destaca nestas novas construções.

A identificação dos problemas de acessibilidade espacial definidos pelos usuários e a aplicação do protocolo de acessibilidade foram instrumentos complementares que permitiram traçar um real diagnóstico dos problemas enfrentados no dia-dia dos moradores destes dois condomínios analisados.

Assim, essa pesquisa visa contribuir para a formulação de programas, projetos e políticas públicas que considerem a importância da acessibilidade em habitações de baixo custo, principalmente a criação de uma fiscalização intensa para verificação o que é executado em 


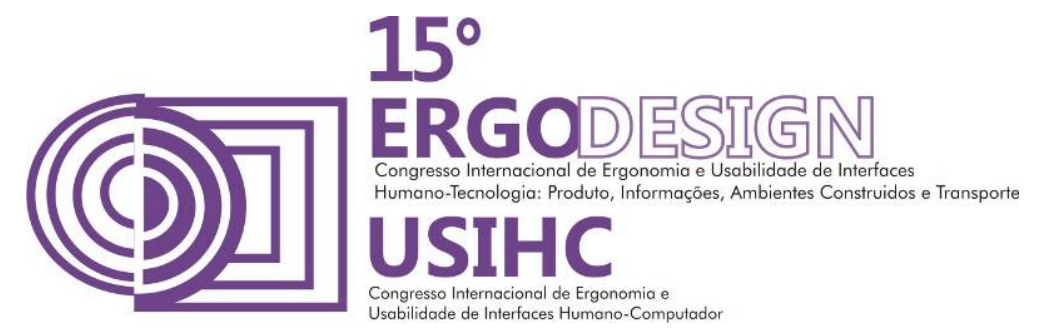

obra, após a aprovação, por órgãos públicos, de projetos arquitetônicos que em teoria atendem ao estipulado na NBR 9050.

\section{REFERÊNCIAS BIBLIOGRÁFICAS}

ASSOCIAÇÃO BRASILEIRA DE NORMAS TÉCNICAS. Norma NBR 9050 - Acessibilidade de pessoas com deficiência a edificações, espaço, mobiliário e equipamentos urbanos. Rio de Janeiro, 2004.

ASSOCIAÇÃO BRASILEIRA DE NORMAS TÉCNICAS. Norma NBR 15575-1 - Edifícios habitacionais de ate cinco pavimentos - Desempenho - Parte 1 Requisitos gerais. Rio de Janeiro, 2010.

BRASIL. Senado Federal. Constituição da República Federativa do Brasil - Constituição (1988). Constituição da República Federativa do Brasil. Brasília, DF: Senado Federal: Centro Gráfico, 1988.

BONDUKI, Nabil. Origens da Habitação Social no Brasil. São Paulo: Estação Liberdade, 2011.

CARLI, Sandra Perito. Moradias inclusivas no mercado habitacional brasileiro. In: PRADO, A. R. de A.; LOPES, M. E.; ORNSTEIN, S. W. (ORG.). Desenho universal: caminhos da acessibilidade no Brasil. São Paulo: Annablume, 2010. p. 131-142.

DISCHINGER, M.; BINS ELY, V. H. M.; PIARDI, S. M. D. G. Promovendo acessibilidade espacial nos edifícios públicos: Programa de Acessibilidade às Pessoas com Deficiência ou Mobilidade Reduzida nas Edificações de Uso Público. Florianópolis: MPSC, 2012.

ORNSTEIN, S.; ROMÉRO, M. Avaliação Pós-Ocupação: métodos e técnicas aplicadas à habitação social. Coleção Habitare. Porto Alegre: Anta, 2003.

PEREIRA, G. M. Acessibilidade espacial na habitação popular: um instrumento para avaliação de projetos. Dissertação (Mestrado) Pós-graduação em Arquitetura e Urbanismo. UFSC. Florianópolis- SC, 2007. 